www.jmscr.igmpublication.org

Impact Factor (SJIF): 6.379

Index Copernicus Value: 71.58

ISSN (e)-2347-176x ISSN (p) 2455-0450

crossref DOI: _https://dx.doi.org/10.18535/jmscr/v6i3.189

Journal Of Medical Science And Clinical Research

IGM Publication

An Official Publication of IGM Publication

\title{
Effect of Central Corneal Thickness on Intraocular Pressure Readings by Goldmann Applanation Tonometer and Non Contact Tonometer
}

\author{
Authors \\ Chitra Raghavan', Swathi Subramanian', V Sahasranamam ${ }^{3}$, Beena Thankappan ${ }^{4}$ \\ Regional Institute of Ophthalmology, Thiruvananthapuram, Kerala, India \\ Corresponding Author \\ V Sahasranamam \\ Director, Regional Institute of Ophthalmology, Thiruvananthapuram-695001 \\ Phone number: +91-9846020421, Email: drsahasranamam@gmail.com
}

\begin{abstract}
Purpose: To study the effect of CCT on IOP readings obtained by NCT and GAT across varying IOP ranges, and to correlate the IOP readings obtained by GAT and NCT.

Methods: 230 eyes were included in this cross sectional study. CCT, IOP by GAT and NCT were measured. Correlation and linear regression between CCT and IOP obtained by GAT and NCT were analysed.

Results: The mean IOP obtained by GAT was $15.64 \pm 6.27 \mathrm{~mm} \mathrm{Hg}$, and that by NCT was $16 \mathrm{mmHg}$. The mean CCT measured was $537.6 \pm 39.3 \mu \mathrm{m}$.IOP by GAT showed a significant positive correlation with CCT $(r=0.78$ and $p<0.001)$. IOP by GAT changes by $1.25 \mathrm{~mm} \mathrm{Hg} \mathrm{per} 10 \mu \mathrm{m}$ change in CCT. IOP by NCT also shows positive correlation with CCT $(r=0.72, p<0.001)$.IOP by NCT changes by $1.21 \mathrm{~mm} \mathrm{Hg}$ per $10 \mu \mathrm{m}$ change in CCT.IOP measured by GAT and NCT showed a significant positive correlation, with highest correlation in the IOP range of $11-20 \mathrm{~mm} \mathrm{Hg}(r=0.719, p<0.001)$.

Conclusion: A significant positive correlation exists between IOP measured by GAT and NCT in all IOP ranges.IOP measured by NCT also significantly correlates with CCT. Change in IOP by NCT is $1.21 \mathrm{~mm}$ $\mathrm{Hg}$ (1.06 to $1.36 \mathrm{~mm} \mathrm{Hg}$ ) per $10 \mu \mathrm{m}$ change in CCT, and is comparable to that by GAT.

Keywords: Intraocular pressure, Goldmann applanation tonometer, noncontact tonometer, glaucoma.
\end{abstract}

\section{Introduction}

Glaucoma is classically described as a chronic progressive optic neuropathy, caused by a group of ocular conditions which lead to damage of optic nerve with loss of visual function. Raised intraocular pressure (IOP) is an important risk factor for glaucoma. Hence, IOP measurement by tonometry plays an important role in both the diagnosis and follow up of patients with glaucoma.
Goldmann applanation tonometer (GAT) is currently the gold standard tonometer ${ }^{1}$, which measures the force needed to flatten a standard area of the cornea, while Noncontact tonometer (NCT) measures the force of air puff to create a standard amount of corneal deformation. A significant advantage with NCT is the elimination of potential hazards associated with all contact tonometers like corneal abrasions, reaction to topical anaesthetic or 
fluoresce in, and spread of infection. However, with NCT, the subject should be able to fixate on the target, limiting its use in patients with poor fixation, nystagmus, and irregular corneal surface.

Central corneal thickness (CCT) emerged as a risk factor for glaucoma in the Ocular Hypertension Treatment Study ${ }^{2}$, which showed that the effect of central corneal thickness may influence the accuracy of applanation tonometry.

This study aims at analysing the effect of CCT on IOP readings obtained by both NCT and GAT across varying IOP ranges and to attempt to arrive at a probable correction formula.

This study also correlates the IOP measured by these two instruments.

\section{Materials and Methods}

This was a cross sectional study performed between January 2015 to January 2016, and enrolled patients visiting Glaucoma Clinic and outpatient department of our institution, after obtaining informed consent. 230 eyes of 130 patients were included. Exclusion criteria were history of previous intraocular surgery/refractive surgery, any corneal pathology, inability to fixate on an object, current corneal or conjunctival infection, astigmatism more than 3 diopters, and secondary glaucomas.

IOP was measured in all patients using both a Goldmann applanation tonometer and a non contact tonometer and recorded in $\mathrm{mmHg}$. Next, central corneal thickness was measured using ultrasound pachymeter (Pacscan 300p - Sonomed). Five consecutive ultrasound pachymetric measurements of CCT was obtained and a mean value was computed and recorded in micrometers. All measurements were performed under topical anaesthesia.

The eyes were stratified on the basis of IOP readings as follows: IOP $\leq 10 \mathrm{mmHg}(\mathrm{n}=77)$, IOP $11-21 \mathrm{mmHg}(\mathrm{n}=77)$, IOP $\geq 21 \mathrm{mmHg}(\mathrm{n}=76)$.

Statistical analysis was doing using Statistical Package for Social Sciences version 20 (SPSS Inc.). A P-value of less than 0.05 was considered to be statistically significant.

\section{Results}

The mean age of patients recruited in this study was $55.6 \pm 4.8$ years. $60.4 \%$ of total patients were female, compared to $39.6 \%$ males. In this study group, $68.7 \%$ of the eyes included had primary open angle glaucoma, whereas $31.3 \%$ had primary angle closure glaucoma.

\section{Measurement of IOP}

Table 1: Mean IOP by GAT in each group

\begin{tabular}{|l|c|c|c|c|c|}
\hline \multirow{2}{*}{ IOP } & \multirow{2}{*}{$\mathrm{N}$} & \multicolumn{2}{|c|}{$\begin{array}{c}\text { GAT (IOP in } \\
\mathrm{mmHg}\end{array}$} & \multirow{2}{*}{$\mathrm{F}$} & $\mathrm{p}$ \\
\cline { 3 - 4 } & & Mean & $\mathrm{Sd}$ & & \\
\hline$\leq 10$ & 77 & 7.76 & 1.00 & \multirow{2}{*}{1677.05} & $<0.001$ \\
\hline $11-20$ & 77 & 16.77 & 1.98 & & \\
\hline$\geq 21$ & 76 & 22.61 & 1.53 & & \\
\hline Total & 230 & 15.64 & 6.27 & & \\
\hline
\end{tabular}

Table 2: Mean IOP by NCT in each group

\begin{tabular}{|l|c|c|c|c|c|}
\hline \multirow{2}{*}{ IOP } & \multirow{2}{*}{$\mathrm{N}$} & \multicolumn{2}{|c|}{$\begin{array}{c}\text { NCT (IOP in } \\
\mathrm{mm} \mathrm{Hg})\end{array}$} & \multirow{2}{*}{$\mathrm{F}$} & \multirow{2}{*}{$\mathrm{p}$} \\
\cline { 3 - 4 } & & Mean & Sd & & \\
\hline$\leq 10$ & 77 & 8.9 & 0.9 & \multirow{2}{*}{1677.05} & $<0.001$ \\
\hline $11-20$ & 77 & 14.8 & 1.8 & & \\
\hline$\geq 21$ & 76 & 24.3 & 2.0 & & \\
\hline Total & 230 & 16.0 & 6.5 & & \\
\hline
\end{tabular}

\section{Central Corneal Thickness}

The mean CCT measured in this study was $537.6 \pm$ $39.3 \mu \mathrm{m}$, with the lowest value obtained being 432 $\mu \mathrm{m}$ and highest $632 \mu \mathrm{m}$.

Fig 1: Bar diagram showing mean CCT in each group

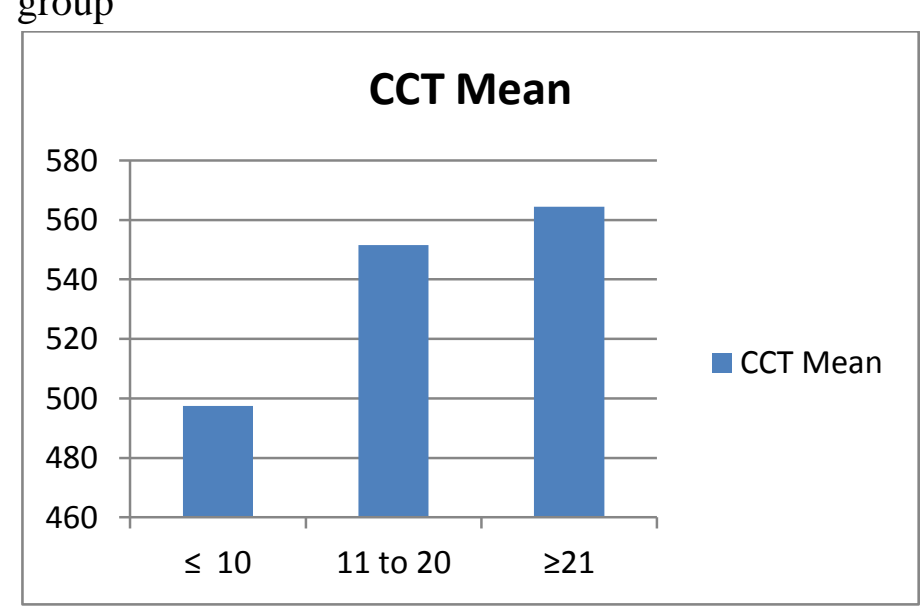

There was a significant difference of CCT among the three groups, with $\mathrm{p}$ value $<0.001$. 


\section{Correlation between CCT and IOP by GAT}

Table 3: Correlation between CCT and IOP by GAT

\begin{tabular}{|l|c|c|}
\hline $\begin{array}{l}\text { Correlation Between CCT } \\
\text { and GAT }(\mathrm{N}=230)\end{array}$ & $\begin{array}{c}\text { Pearson } \\
\text { Correlation } \mathrm{r}\end{array}$ & $\mathrm{P}$ \\
\hline Whole data $(\mathrm{N}=230)$ & .784 & $<0.001$ \\
\hline In GAT $\leq 10$ group & .470 & $<0.001$ \\
\hline In GAT 11-20 group & .631 & $<0.001$ \\
\hline GAT $\geq 21$ group & .450 & $<0.001$ \\
\hline
\end{tabular}

IOP by Goldmann applanation tonometry showed a significant positive correlation with CCT with $\mathrm{r}=$ 0.78 and $\mathrm{p}<0.001$.

IOP and CCT showed a significant positive correlation in all three groups; with highest correlation in the normal IOP range;

$\mathrm{r}=0.47, \mathrm{p}<0.001$ in $\mathrm{IOP} \leq 10 \mathrm{~mm} \mathrm{Hg}$

$\mathrm{r}=0.63, \mathrm{p}<0.001$ in IOP $11-20 \mathrm{~mm} \mathrm{Hg}$

$r=0.45, p<0.001$ in IOP $\geq 21 \mathrm{~mm} \mathrm{Hg}$.

Table 4: Linear regression for CCT with IOP by GAT

\begin{tabular}{|c|c|c|c|c|c|c|c|}
\hline \multirow[b]{2}{*}{ Model } & \multicolumn{2}{|c|}{$\begin{array}{l}\text { Unstandardi } \\
\text { zed } \\
\text { Coefficients }\end{array}$} & \multirow{2}{*}{\begin{tabular}{|c}
$\begin{array}{c}\text { Standardiz } \\
\text { ed } \\
\text { Coefficient } \\
\text { s }\end{array}$ \\
Beta \\
\end{tabular}} & & \multirow[b]{2}{*}{$P$} & \multicolumn{2}{|c|}{$\begin{array}{c}95.0 \% \\
\text { Confidence } \\
\text { Interval for B }\end{array}$} \\
\hline & B & \begin{tabular}{|l} 
Std. \\
Errol
\end{tabular} & & & & $\begin{array}{l}\text { Lower } \\
\text { Bound }\end{array}$ & $\begin{array}{l}\text { Upper } \\
\text { Bound }\end{array}$ \\
\hline $\begin{array}{l}\text { (Const } \\
\text { ant) }\end{array}$ & 51.785 & $\begin{array}{c}3.54 \\
5\end{array}$ & & $\begin{array}{c}- \\
14.61 \\
0\end{array}$ & .000 & -58.769 & $\begin{array}{c}- \\
44.800\end{array}$ \\
\hline CCT & .125 & .007 & .784 & $\begin{array}{c}19.07 \\
3\end{array}$ & .000 & .112 & .138 \\
\hline
\end{tabular}

a. Dependent Variable: GAT

From the above linear regression model, the following conclusions can be arrived at:

- $\quad$ IOP by GAT $=-51.785+0.125 \times$ CCT

- For $1 \mu \mathrm{m}$ change in CCT, the IOP measured by GAT changes by $0.125 \mathrm{~mm} \mathrm{Hg}$

- IOP by GAT changes by $1.25 \mathrm{~mm} \mathrm{Hg}$ per 10 $\mu \mathrm{m}$ change in $\mathrm{CCT}$

- The change in IOP by GAT can range from 1.12 to $1.38 \mathrm{~mm} \mathrm{Hg}$ per $10 \mu \mathrm{m}$ change in CCT

\section{Correlation of CCT with IOP by NCT}

Table 5: Correlation between CCT and IOP by NCT

\begin{tabular}{|l|c|c|}
\hline Correlation of NCT with CCT & $\begin{array}{c}\text { Pearson } \\
\text { Correlation } r\end{array}$ & P \\
\hline TOTAL $(\mathrm{N}=230)$ & .727 & 0.000 \\
\hline IOP $\leq 10 \mathrm{~mm} \mathrm{Hg}$ & .572 & 0.000 \\
\hline IOP $11-20 \mathrm{~mm} \mathrm{Hg}$ & .714 & 0.000 \\
\hline IOP $\geq 21 \mathrm{~mm} \mathrm{Hg}$ & .394 & 0.000 \\
\hline
\end{tabular}

IOP by NCT showed a significant positive correlation with CCT, with $\mathrm{r}=0.72, \mathrm{p}<0.001$.

There was a significantly positive correlation between CCT and IOP in each subgroup as well; with highest correlation in normal IOP range;

- $\mathrm{r}=0.57, \mathrm{p}<0.001$ in $\mathrm{IOP} \leq 10 \mathrm{~mm} \mathrm{Hg}$

- $\mathrm{r}=0.71, \mathrm{p}<0.001$ in IOP $11-20 \mathrm{~mm} \mathrm{Hg}$

- $\mathrm{r}=0.39, \mathrm{p}<0.001$ in IOP $\geq 21 \mathrm{~mm} \mathrm{Hg}$

Table 6: Linear regression for CCT with IOP by NCT

\begin{tabular}{|c|c|c|c|c|c|c|c|c|}
\hline \multirow{2}{*}{\multicolumn{2}{|c|}{ Model }} & \multicolumn{2}{|c|}{$\begin{array}{l}\text { Unstanda } \\
\text { rdized } \\
\text { Coefficie } \\
\text { nts }\end{array}$} & \multirow{2}{*}{$\begin{array}{l}\text { Standa } \\
\text { rdized } \\
\text { Coeffi } \\
\text { cients } \\
\text { Beta }\end{array}$} & \multirow[b]{2}{*}{$\mathrm{T}$} & \multirow[b]{2}{*}{ Sig. } & \multicolumn{2}{|c|}{$\begin{array}{l}95.0 \% \text { Confidence } \\
\text { Interval for B }\end{array}$} \\
\hline & & B & $\begin{array}{l}\text { Std. } \\
\text { Erro } \\
r\end{array}$ & & & & $\begin{array}{l}\text { Lower } \\
\text { Bound }\end{array}$ & $\begin{array}{l}\text { Upper } \\
\text { Bound }\end{array}$ \\
\hline \multirow[t]{2}{*}{1} & $\begin{array}{l}\text { (Co } \\
\text { nsta } \\
\text { nt) }\end{array}$ & $\begin{array}{l}- \\
48 . \\
93 \\
4\end{array}$ & $\begin{array}{l}4.07 \\
5\end{array}$ & & $\begin{array}{l}- \\
12.0 \\
08\end{array}$ & .000 & $\begin{array}{l}- \\
56.964\end{array}$ & -40.904 \\
\hline & CCT & $\begin{array}{l}.12 \\
1\end{array}$ & .008 & .727 & $\begin{array}{l}15.9 \\
74\end{array}$ & .000 & .106 & .136 \\
\hline
\end{tabular}

a. Dependent Variable: NCT

From the above linear regression model, the following conclusions can be drawn:

- $\quad$ IOP by NCT $=-48.934+0.121 \times$ CCT

- For $1 \mu \mathrm{m}$ change in CCT, IOP by NCT changes by $0.121 \mathrm{~mm} \mathrm{Hg}$

- IOP by NCT changes by $1.21 \mathrm{~mm} \mathrm{Hg}$ per 10 $\mu \mathrm{m}$ change in $\mathrm{CCT}$.

- The change in IOP by NCT can range from 1.06 to $1.36 \mathrm{~mm} \mathrm{Hg}$ per $10 \mu \mathrm{m}$ change in CCT. 
Correlation of IOP measured by GAT and NCT

Table 7: Correlation of IOP by GAT and NCT

\begin{tabular}{|l|c|c|}
\hline $\begin{array}{l}\text { Correlation of NCT with } \\
\text { GAT }\end{array}$ & $\begin{array}{c}\text { Pearson Correlation } \\
\mathrm{r}\end{array}$ & $\mathrm{P}$ \\
\hline TOTAL $(\mathrm{N}=230)$ & .952 & $<0.001$ \\
\hline IOP $\leq 10 \mathrm{~mm} \mathrm{Hg}$ & .626 & $<0.001$ \\
\hline IOP $11-20 \mathrm{~mm} \mathrm{Hg}$ & .719 & $<0.001$ \\
\hline IOP $\geq 21 \mathrm{~mm} \mathrm{Hg}$ & .685 & $<0.001$ \\
\hline
\end{tabular}

IOP measured by GAT and NCT showed a significant positive correlation, with $\mathrm{r}=0.952, \mathrm{P}<$ 0.001 , with highest correlation in the IOP range of $11-20 \mathrm{~mm} \mathrm{Hg}(\mathrm{r}=0.719, \mathrm{p}<0.001)$.

\section{Discussion}

This study was done to evaluate the effects of central corneal thickness on IOP measured by both GAT and NCT, among varying ranges of IOP, and also to correlate the IOP obtained by these two tonometers.

\section{Central Corneal Thickness}

The mean CCT measured in this study was $537.6 \pm$ $39.3 \mu \mathrm{m}$, with the lowest value obtained being 432 $\mu \mathrm{m}$ and highest $632 \mu \mathrm{m}$. This is similar to a study done in Indian population, which found the mean CCT to be $536 \pm 19 \mu \mathrm{m}^{3}$.

\section{Correlation of IOP with CCT}

The present study found a significantly positive correlation between IOP by both GAT and NCT with CCT in all IOP ranges.

A study on 100 patients of POAG, PACG, OHT, and NTG concluded that measurements of IOP by NCT are more affected by CCT than GAT and hence, CCT can influence the discordance of IOP readings taken with NCT significantly, whereas only minor influence is observed with $\mathrm{GAT}^{4}$. A study on 135 eyes of healthy subjects showed that there was a significant correlation between CCT with both NCT $(r=0.260, p=0.003)$ and GAT measurements $(r=0.257, p=0.005)^{5}$. Linear regression analysis in our study showed that IOP by NCT changes by $1.21 \mathrm{~mm} \mathrm{Hg}$ per $10 \mu \mathrm{m}$ change in CCT and that IOP by GAT changes by $1.25 \mathrm{~mm} \mathrm{Hg}$ per $10 \mu \mathrm{m}$ change in CCT. A study by Vinay Gupta et $\mathrm{al}^{6}$ showed that NCT were more affected by corneal thickness $(0.4 \mathrm{mmHg} / 10 \mu$ corneal thickness) while GAT was the least affected by corneal thickness $(0.3 \mathrm{mmHg} / 10 \mu$ corneal thickness) though the difference was not statistically significant $(\mathrm{P}=0.42)$. In a population-based study, Eysteinsson et $\mathrm{al}^{7}$ found $0.22-0.28 \mathrm{mmHg}$ correction for 10 microns change in CCT using NCT (Nidek 2000).

A previous study ${ }^{5}$ using linear regression analysis showed a mean change of $2.1 \mathrm{mmHg}$ in IOP measured by NCT and $1.9 \mathrm{mmHg}$ in IOP measured by GAT per $10 \mu \mathrm{m}$ variation in CCT. A higher regression coefficient was obtained in a study by Ko $\mathrm{YC}$ et $\mathrm{al}^{8}$, where the NCT measurements showed the greatest regression coefficient $(\beta=0.063, \mathrm{r}=$ 0.650 ), while the GAT measurements showed the least regression coefficient $(\beta=0.037, r=0.496)$ Their study also showed that every $10 \mu \mathrm{m}$ change in CCT would yield a $0.98 \mathrm{mmHg}$ deviation in NCT measurements $(r=0.896)$.

The correlation between IOP obtained by GAT and NCT was significant in all three IOP ranges in the present study. IOP measured by GAT and NCT showed a significant positive correlation, with $\mathrm{r}=$ $0.952, \mathrm{P}<0.001$. The highest correlation was seen in IOP ranging from 11 to $20 \mathrm{~mm} \mathrm{Hg}$.

A study by $\mathrm{S}$ Mohan et $\mathrm{al}^{3}$ showed a positive Pearson's correlation coefficient of 0.909 between GAT and NCT. Further analysis showed a fair agreement between the two tonometers in the lower IOP range. They concluded that NCT can be used as a screening tool in the community but is not reliable in subjects with higher IOP range. Another study ${ }^{9}$ concluded that the CT80 NCT provides IOP measurements that are comparable to those obtained by the GAT in patients with normal and high IOP. Our study shows that values obtained by NCT can be reliable across a wider range of IOP and has a similar correction factor with respect to CCT.

\section{Conclusion}

A significant positive correlation exists between IOP measured by GAT and NCT. Change in IOP by GAT is $1.25 \mathrm{~mm} \mathrm{Hg}(1.12-1.38 \mathrm{~mm} \mathrm{Hg})$ per 10 $\mu \mathrm{m}$ change in CCT. IOP measured by NCT also 
significantly correlates with CCT. Change in IOP by NCT is $1.21 \mathrm{~mm} \mathrm{Hg}$ (1.06 to $1.36 \mathrm{~mm} \mathrm{Hg}$ ) per 10 $\mu \mathrm{m}$ change in CCT. IOP measured by NCT and GAT have significant correlation in all IOP ranges.

\section{References}

1. Goldmann H, Schmidt T. Applanation tonometry [in German]. Ophthalmologica 1957;134:221-42.

2. Brandt JD, Beiser JA, Kass MA, et al. Central corneal thickness in the Ocular Hypertension Treatment Study (OHTS). Ophthalmology. 2001; 108(10):1779-1788

3. Mohan S, Tiwari S, Jain A, Gupta J,Sachan S. K. (2014). Clinical comparison of Pulsair non-contact tonometer and Goldmann applanation tonometer in Indian population. Journal of Optometry, 7(2), 86-90

4. Patel Himadri L, Singh Punit V, Kothari Raghunandan N, Desai Vivan D, Jain Jayesh, Siddharth Dua. To study the influence of central corneal thickness on intraocular pressure, measured by noncontact and Goldmann applanation tonometers in glaucomatous patients. International Journal of Research in Health Sciences 2015 Volume-3, Issue-4

5. Aysel Pelit, Rana Altan-Yaycioglu, Aykut Pelit, Yonca A. Effect of corneal thickness on intraocular pressure measurements with the Pascal dynamic contour, Canon TX-10 non-contact and Goldmann applanation tonometers in healthy subjects. Clin Exp Optom 2009; 92: 1: 14-18

6. Viney Gupta, Parul Sony, Harish C Agarwal, Ramanjit Sihota, Ajay Sharma. Inter-instrument agreement and influence of central corneal thickness on measurements with Goldmann, pneumotonometer and noncontact tonometer in glaucomatous eyes. Indian J Ophthalmol 2006;54:261-5

7. Eysteinsson $T$, Jonasson $F$, Sasaki $H$, Arnarsson A, Sverrisson T, Sasaki K, et al. Central corneal thickness, radius of curvature and intraocular pressure in normal subjects using non contact techniques: Reykjavik eye study. Acta Ophthalmol Scand 2002;80:11-15.

8. Ko YC, Liu CJ, Hsu WM. Varying effects of corneal thickness on intraocular pressure measurements with different tonometers. Eye 2005;19:327-332

9. Abdulrahman et al. Comparison of the CT80 Non-Contact Tonometer and Goldmann Applanation Tonometer .Med. J. Cairo Univ., Vol. 79, No. 2, December: 9-11, 2011. 